\title{
BLANK ASSESSMENT FOR ULTRA-SMALL RADIOCARBON SAMPLES: CHEMICAL EXTRACTION AND SEPARATION VERSUS AMS
}

\author{
Guaciara M Santos ${ }^{1,2} \bullet$ John R Southon $^{1} \cdot$ Nicholas J Drenzek $^{3} \bullet$ Lori A Ziolkowski $^{1} \bullet$ Ellen Druffel $^{1} \bullet$ \\ Xiaomei $\mathrm{Xu}^{1} \bullet$ Dachun Zhang ${ }^{1} \bullet$ Susan Trumbore ${ }^{1,4} \cdot$ Timothy I Eglinton $^{3} \bullet$ Konrad A Hughen $^{3}$ \\ ABSTRACT. The Keck Carbon Cycle AMS facility at the University of California, Irvine (KCCAMS/UCI) has developed \\ protocols for analyzing radiocarbon in samples as small as $\sim 0.001 \mathrm{mg}$ of carbon (C). Mass-balance background corrections \\ for modern and ${ }^{14} \mathrm{C}$-dead carbon contamination (MC and DC, respectively) can be assessed by measuring ${ }^{14} \mathrm{C}$-free and mod- \\ ern standards, respectively, using the same sample processing techniques that are applied to unknown samples. This approach \\ can be validated by measuring secondary standards of similar size and ${ }^{14} \mathrm{C}$ composition to the unknown samples. Ordinary \\ sample processing (such as ABA or leaching pretreatment, combustion/graphitization, and handling) introduces MC contam- \\ ination of $\sim 0.6 \pm 0.3 \mu \mathrm{g} \mathrm{C}$, while $\mathrm{DC}$ is $\sim 0.3 \pm 0.15 \mu \mathrm{g} \mathrm{C}$. Today, the laboratory routinely analyzes graphite samples as small \\ as $0.015 \mathrm{mgC}$ for external submissions and $\cong 0.001 \mathrm{mg} \mathrm{C}$ for internal research activities with a precision of $\sim 1 \%$ for $\sim 0.010$ \\ $\mathrm{mg} \mathrm{C}$. However, when analyzing ultra-small samples isolated by a series of complex chemical and chromatographic methods \\ (such as individual compounds), integrated procedural blanks may be far larger and more variable than those associated with \\ combustion/graphitization alone. In some instances, the mass ratio of these blanks to the compounds of interest may be so \\ high that the reported ${ }^{14} \mathrm{C}$ results are meaningless. Thus, the abundance and variability of both $\mathrm{MC}$ and $\mathrm{DC}$ contamination \\ encountered during ultra-small sample analysis must be carefully and thoroughly evaluated. Four case studies are presented \\ to illustrate how extraction chemistry blanks are determined.
}

\section{INTRODUCTION}

Following the advent of compound-specific radiocarbon analysis (CSRA) (Eglinton et al. 1996), it became clear that the full potential of the technique was constrained by 2 basic considerations: (1) the purity to which material could be chromatographically isolated; and (2) the capability of accelerator mass spectrometry (AMS) systems to accurately measure very small-mass C targets (Ingalls and Pearson 2005).

The Keck Carbon Cycle AMS facility at the University of California, Irvine (KCCAMS/UCI) has demonstrated the analytical capability to accurately measure the ${ }^{14} \mathrm{C}$ content of graphite samples far smaller than $0.100 \mathrm{mg} \mathrm{C}$ (Santos et al. 2007a,c, 2010). However, procedural blanks in environmental samples that are subjected to complex extraction/isolation procedures before conversion to $\mathrm{CO}_{2}$ and graphite are normally larger than those arising during these latter processes (Hwang et al. 2005; Beaupré et al. 2007; Santos et al. 2010), and become even more critical when samples are small $(<0.100 \mathrm{mg} \mathrm{C})$. As the use of CSRA techniques increases and sample demands trend toward the ultra-small range $(<0.020 \mathrm{mg} \mathrm{C})$, this procedural blank can place a practical limit to overall accuracy and precision (Pearson et al. 2005; Ingalls et al. 2006; Shah and Pearson 2007). Zencak et al. (2007) found no measurable carbon contamination from CSRA analysis, but they focused on the blank from the preparative capillary gas chromatography (PCGC) separation only, and the study used large samples $(0.060-0.92 \mathrm{mg} \mathrm{C})$.

In the first part of this work, we show detailed data sets of regular $(1 \mathrm{mg} \mathrm{C})$ to ultra-small $(0.002 \mathrm{mg}$ C) aliquots of ${ }^{14} \mathrm{C}$-free samples and secondary standards (NIST OX-I; FIRI-C and FIRI-D; IAEA-

${ }^{1}$ KCCAMS Facility, Earth System Science Department, B321 Croul Hall, University of California, Irvine, California $92697-$ 3100 , USA.

${ }^{2}$ Corresponding author. Email: gdossant@uci.edu.

${ }^{3}$ Department of Marine Chemistry and Geochemistry, Woods Hole Oceanographic Institution, Woods Hole, Massachusetts 02543, USA.

${ }^{4}$ Max-Planck Institute for Biogeochemistry, Jena D-07745, Germany.

(C) 2010 by the Arizona Board of Regents on behalf of the University of Arizona Proceedings of the 20th International Radiocarbon Conference, edited by A J T Jull RADIOCARBON, Vol 52, Nr 2-3, 2010, p 1322-1335 
C6, -C7, and -C8) measured since 2005. These results help us to evaluate our overall performance when dealing with small samples by (a) checking sample preparation protocols and sample size limits, (b) quantifying the AMS laboratory processing background, (c) verifying background subtraction formulas and propagated errors, and (d) checking measurement accuracy and precision. In the second part, we show CSRA blank assessments from 4 case studies to illustrate that this chemistry blank cannot be overlooked, because even a small amount of $\mathrm{C}$ contamination can critically distort the final ${ }^{14} \mathrm{C}$ results. For example, one cannot assume that preparative (gas or liquid) chromatography systems do not introduce $\mathrm{C}$ contamination during the isolation of individual organic compounds, nor that the preceding chemical reaction and speciation protocols generate only pure products.

\section{CONTAMINATION SOURCES AND MITIGATION STRATEGIES FOR ${ }^{14} \mathrm{C}$ AMS BLANKS}

The advantage of directly counting ${ }^{14} \mathrm{C}$ atoms with AMS technology initially suggested that smaller and perhaps much older samples (100 ka BP) could be handled and measured (Muller 1977; Nelson et al. 1977). However, the lower age limit of $\sim 60 \mathrm{ka} \mathrm{BP}$ is mainly constrained by the introduction of $\mathrm{C}$ during sample preparation and consequently varies depending on the complexity of the procedures to which samples are subjected. Over time, ${ }^{14} \mathrm{C}$ labs have been able to identify and remove $\mathrm{C}$ contamination introduced in situ (i.e. from sample surroundings), and also during chemical pretreatment protocols applied to remove most of the in situ C (e.g. acid and base hydrolysis of organics, leaching and hydrolysis of carbonates, cellulose extractions of wood samples, and extraction and ultrafiltration of collagen from tooth and bone samples) (Olson 2009). The carbon in the sample $\left(\mathrm{C}_{s}\right)$ to be measured on the AMS is from 2 sources:

$$
\mathrm{C}_{s}=\mathrm{C}+\mathrm{C}_{i}
$$

where $\mathrm{C}$ is the carbon of interest and $\mathrm{C}_{i}$ is the mobile carbon that needs to be removed during chemical pretreatment. However, after any AMS sample preparation process the actual C content measured at the AMS system can be express as:

$$
\mathrm{C}_{A M S}=\mathrm{C}_{s}-\alpha \mathrm{C}_{i}+\mathrm{C}_{c}+\mathrm{C}_{h}
$$

where $\alpha \mathrm{C}_{i}$ is the amount of $\mathrm{C}$ contamination removed ( $\left.\alpha \leq 1\right), \mathrm{C}_{c}$ is the $\mathrm{C}$ introduced by any chemical pretreatment applied, and $\mathrm{C}_{h}$ is the combination of extra carbon added during combustion/ graphitization (procedures necessary to produce solid AMS targets), graphite handling, and the spectrometer during measurement (note that $\mathrm{C}_{c}$ and $\mathrm{C}_{h}$ are typically $<<\mathrm{C}_{i}$ ). Because most of the $\mathrm{C}$ contamination removed from or added to larger samples is from contemporary sources (although it is known that some ${ }^{14} \mathrm{C}$-free carbon is also present- the DC component-see below), the $\mathrm{C}_{c}$ and $\mathrm{C}_{h}$ fractions are normally quantified (combined or separately) by processing and measuring ${ }^{14} \mathrm{C}$-free materials or blanks (i.e. those whose ${ }^{14} \mathrm{C}$ content is known to be below AMS detection limits) alongside the unknown samples. Frequent evaluation of these blanks is necessary in order to capture the variability arising from different lab techniques and equipment in addition to intrinsic sample heterogeneity.

To date, the reduction of the backgrounds from AMS sample preparation is still a concern for many labs. At the KCCAMS preparation lab, the following steps have allowed us to obtain background results as low as $0.07 \mathrm{pMC}(\sim 58 \mathrm{ka} \mathrm{yr} \mathrm{BP})$ on ${ }^{14} \mathrm{C}$-free samples of $>0.7 \mathrm{mg} \mathrm{C}$ (Beverly et al. 2010) by: a) chemical pretreatment of carbonate samples in the same vials used for $\mathrm{CO}_{2}$ production (hydrolysis) to reduce sample contact with unnecessary additional surfaces (Santos et al. 2004); b) biweekly baking in air at high temperature $\left(900^{\circ} \mathrm{C}\right)$ of the reagents used during organic combustion ( $\mathrm{CuO}$ and $\mathrm{Ag}$ wires); c) combusting organic samples with no more than $60 \mathrm{mg}$ of prebaked $\mathrm{CuO}$ 
wire to produce a $1.0 \mathrm{mg} \mathrm{C}$ graphite target (5:1 mole ratio of $\mathrm{O}: \mathrm{C})$; $\mathrm{d})$ combusting samples in narrow $(6 \mathrm{~mm} \mathrm{OD})$ and short ( $\leq 15 \mathrm{~cm}$ long) prebaked quartz tubes to minimize surface area; and e) frequent checking of $\mathrm{C}$ contamination levels in reagents and Fe catalyst purchased (Santos et al. 2007b). In addition, just before graphitization, the $\mathrm{Fe}$ catalyst is prebaked in the graphitization reactors at $400{ }^{\circ} \mathrm{C}$ for $\sim 1 \mathrm{hr}$ in 1 atmosphere of $\mathrm{H}_{2}$.

As sample sizes decrease, the effect of contaminant carbon on blanks becomes more prominent (Vogel et al. 1987; Kirner et al. 1995). This inversely proportional dependence has been studied by using a simple model that assumed a constant mass of modern C (MC) (Brown and Southon 1997). ${ }^{5}$ A contamination of dead C (DC) was also suggested due to fossil carbon addition. In this case, both $\mathrm{MC}$ and $\mathrm{DC}$ contaminations can be present during ${ }^{14} \mathrm{C}$ AMS sample processing; however, DC is usually smaller than $\mathrm{MC}$ and becomes detectable only when samples sizes are very small $(<<0.100$ $\mathrm{mg} \mathrm{C}$ ).

Santos et al. (2007a) developed formulas to correct the MC and DC contributions separately from unknown samples as small as $\sim 0.001 \mathrm{mg} \mathrm{C}$ (Santos et al. 2007c, 2010). To quantify the MC component from any batch of unknown samples, we subject smaller ${ }^{14} \mathrm{C}$-free blanks to the same sample pretreatment as the unknowns. Figure 1a shows detailed plots of regular (1 mg C) to ultra-small nominally ${ }^{14} \mathrm{C}$-free samples (dead wood, calcite, and coal blanks) measured since 2005 . Note that the ratio of the ${ }^{14} \mathrm{C}$-free sample activity to that of OX-I for all 3 sample types overlap, indicating that the chemical pretreatment procedures for each type introduce similar amounts of MC contamination. Samples $<0.1 \mathrm{mg} \mathrm{C}$ show an average $\mathrm{MC}$ contamination of $0.6 \pm 0.3 \mathrm{mg} \mathrm{C}$ and a linear trend. For samples $>0.1 \mathrm{mg} \mathrm{C}$, the $\mathrm{MC}$ contamination trend typically flattens and backgrounds become constant for graphite targets $>0.7 \mathrm{mg} \mathrm{C}$. To detect and quantify any DC contamination introduced during combustion and graphitization, we produce and measure smaller modern standards (graphite targets of OX-I $\leq 0.100 \mathrm{mg} \mathrm{C}$, used here as a modern "blank"). Figure $1 \mathrm{~b}$ shows the deviations of the measured ratios of those smaller modern standards to the expected mean value from the normalizing primary standard set (1 mg C OX-I) measured in the same wheels. For clarity of DC variability, a subset with only 90 results was plotted. Our DC contamination is typically $\sim 0.30 \pm 0.15 \mu \mathrm{g} \mathrm{C}$. Note that in principle both sources of carbon contamination (MC and DC) will be present in the $\mathrm{C}_{c}$ and $\mathrm{C}_{h}$ fractions (Equation 2); consequently, DC and MC blank contributions should both be determined for the full sample processing. However, results on small aliquots of pretreated secondary standards show that most of the C contamination from conventional AMS chemical treatments (e.g. acid-baseacid on organics, leaching and hydrolyses of carbonates) is from contemporary sources. We therefore typically use combustion/graphitization DC estimates for correcting non-CSRA samples.

Figure 2a shows corrected OX-I ${ }^{14} \mathrm{C}$ results from the full set of smaller samples measured since 2005 $(n=610)$. The uncertainties in the background corrections for DC contamination applied to these final OX-I ${ }^{14} \mathrm{C}$ results (derived from the scatter of the data in Figure $1 \mathrm{~b}$ ) are reflected in the propagated errors and are particularly evident at the ultra-small level. In Figure $2 b$, we plot the mean online $\delta^{13} \mathrm{C}$ AMS values from the same 610 aliquots shown in Figure 2a. These results will be discussed further below.

\footnotetext{
${ }^{5}$ For ${ }^{14} \mathrm{C}$ dating, the term "modern" is strictly associated with ${ }^{14} \mathrm{C}$ activity that corresponds to the calendar age of AD 1950. In this work, the term "modern" is used loosely to define near-contemporary carbon contamination that will tend to shift the ${ }^{14} \mathrm{C}$ signature of samples to younger values.
} 

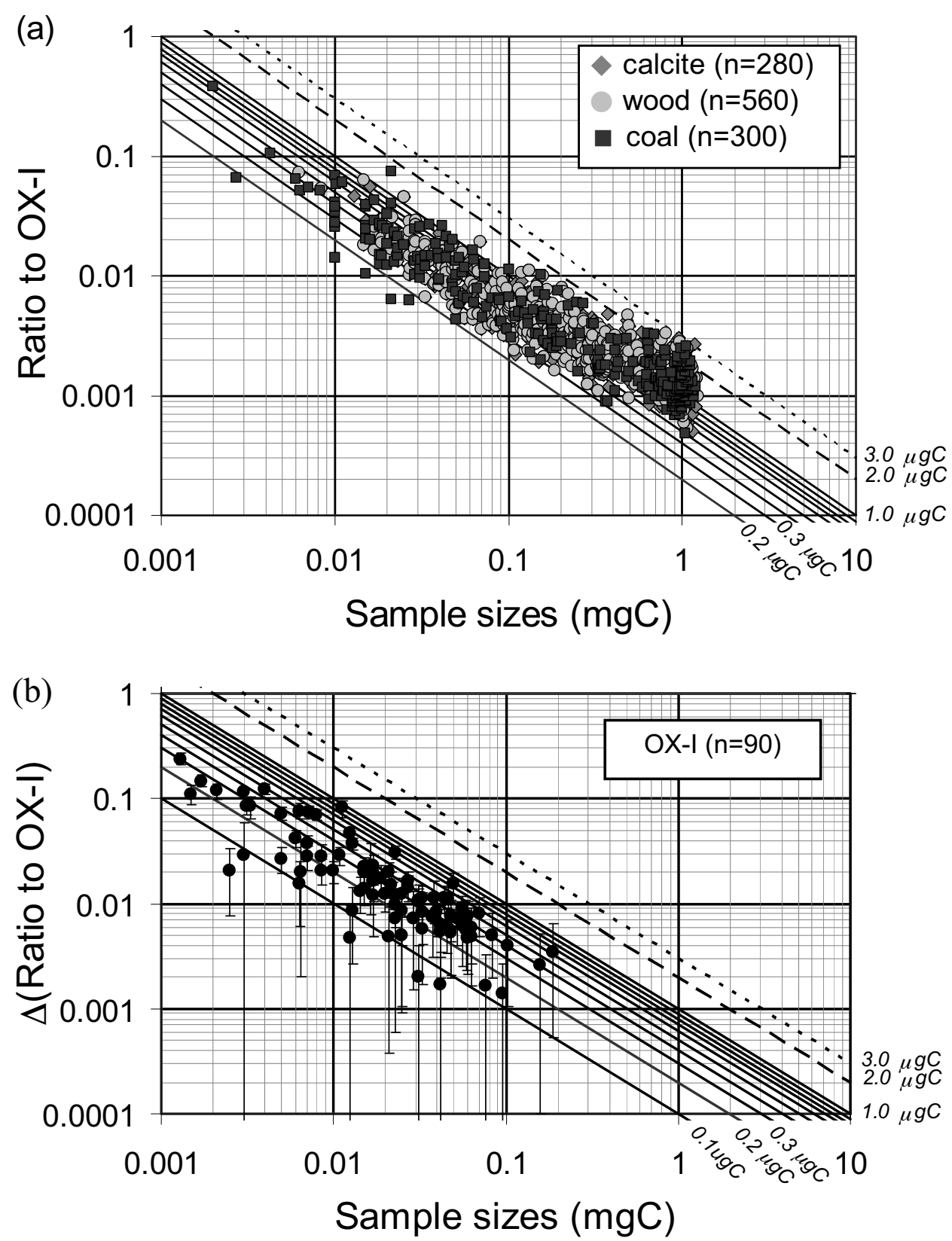

Figure 1 (a) to quantify the modern carbon (MC) contamination, ratios to OX-I (modern C standard) are shown for ${ }^{14} \mathrm{C}$-free blanks (from 0.002 to $1 \mathrm{mg} \mathrm{C}$ ) subjected to conventional acid/base/acid washes (organics: coal and wood blank) or surface leaching (carbonates: calcite); (b) to quantify the dead carbon (DC) component: fractional deviations of the ratios of small and ultra-small OX-I samples $(n=90)$ of $\sim 0.0015$ to $0.2 \mathrm{mg}$ $\mathrm{C}$ from those of the 1-mg C normalizing OX-I standards. Note that uncorrected ${ }^{14} \mathrm{C}$ results from smaller OXI samples are always depleted (e.g. fraction modern $\mathrm{C}$ values are lower than consensus values - see Figure 7a in Santos et al. 2007c). Error bars represent propagated errors. All results shown have been corrected for machine fractionation $\delta^{13} \mathrm{C}$ AMS. Diagonal lines in both plots represent fixed amounts of carbon contamination from 0.1 to $3 \mu \mathrm{g} \mathrm{C}$. 

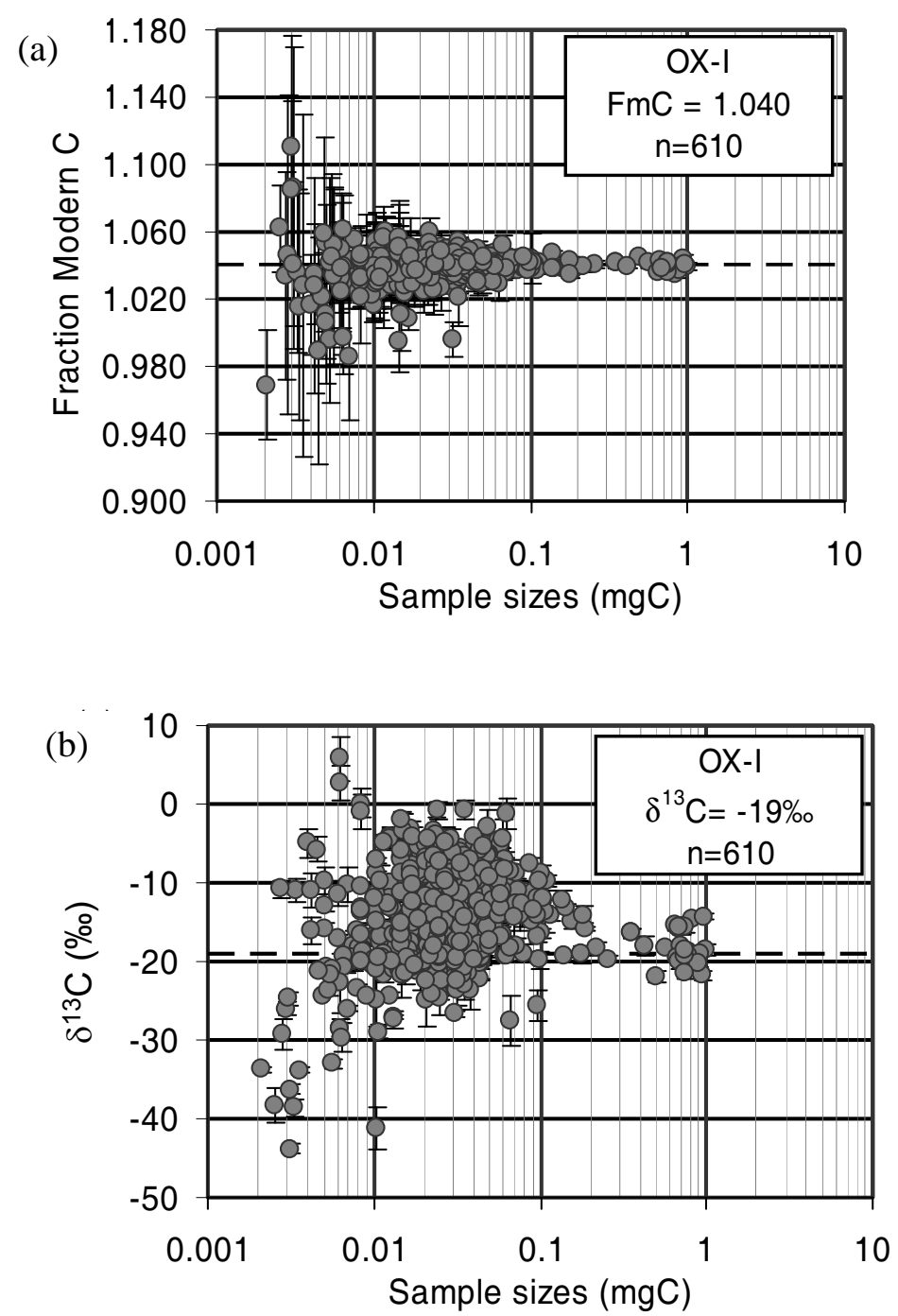

Figure 2 (a) Fraction modern carbon results for OX-I samples between 0.002 and $\sim 1$ $\mathrm{mg} \mathrm{C}$ from multiple ${ }^{14} \mathrm{C}$ AMS measurements are shown. All results have been corrected for fractionation using $\delta^{13} \mathrm{C}$ AMS measurements, and for $\mathrm{MC}$ and $\mathrm{DC}$, contamination (blank subtraction formulas presented in Santos et al. 2007a); (b) illustrates the importance of correcting results with on-line $\delta^{13} \mathrm{C}$ AMS (which includes a correction for machine-induced isotopic fractionation) to achieve reliable results.

The requirements for achieving good accuracy and precision on small samples are (Santos 2007c):

- High graphite yield ( 100\%) and accurate determination of sample sizes: obtained by using small volume graphite reactors, adequate Fe powder catalyst, $\mathrm{Mg}\left(\mathrm{ClO}_{4}\right)_{2}$ to trap $\mathrm{H}_{2} \mathrm{O}$ during reaction, and sensitive pressure transducers (Santos et al. 2004, 2007a,b).

- High, long-lasting beam currents: our modified NEC MC-SNICS ion source delivers $\sim 1 \mu \mathrm{A}$ of ${ }^{12} \mathrm{C}^{+}$per $\mu \mathrm{g} \mathrm{C}$ and allows us to obtained good statistics $\left(4-5 \%\right.$ of the ${ }^{14} \mathrm{C}$ atoms measured in samples $<0.010 \mathrm{mg} \mathrm{C}$; Southon and Santos 2007). 
- Correcting machine-induced isotopic fractionation with on-line $\delta^{13} \mathrm{C}$ AMS instead of $\delta^{13} \mathrm{C}$ IRMS values (our usual procedure for all samples, regardless of size): Early AMS results from small samples showed that small graphite targets were indeed prone to machine-induced isotopic fractionation, in particular for samples with $<0.1 \mathrm{mg} \mathrm{C}$ (Santos et al. 2007c). However, we did not have enough data to address any systematic size dependency to lower or higher $\delta^{13} \mathrm{C}$ values. In Figure $2 \mathrm{~b}$, we plot the mean on-line $\delta^{13} \mathrm{C}$ AMS values from 0.002 to $1 \mathrm{mg} \mathrm{C}$. Between 0.010 and $0.1 \mathrm{mg} \mathrm{C}$, the scatter of $\delta^{13} \mathrm{C}$ values increases from $\pm 4 \%$ to $\pm 25 \%$ with a tendency toward higher values; however, beyond $<0.01 \mathrm{mg} \mathrm{C}$, the trend reverses and the overall scatter can be as large as $\pm 45 \%$. This tendency in the OX-I $\delta^{13} \mathrm{C}$ data is similar to that for all other small standards measured (Figure 3). To account for this spectrometer-induced isotopic fractionation, we correct the "raw" ${ }^{14} \mathrm{C} /{ }^{12} \mathrm{C}$ ratio acquired during a single sputtering period $(100$ $150 \mathrm{~s}$ ) with its own on-line $\delta^{13} \mathrm{C}$ value. Although few studies on negative ion-source and spectrometer-induced isotopic fractionation are available (Middleton et al. 1994 and references therein; Quarta et al. 2004), they suggest that severe isotopic fractionation $(\sim 10 \%)$ is expected during AMS measurements. Consequently, the possibility of sample-to-sample differences in fractionation exists, and the $\delta^{13} \mathrm{C}$ data produced by the AMS spectrometer may differ significantly from the actual isotopic signature of the material measured. In our case, sample-to-sample spectrometer-induced isotopic fractionation variability may be also influenced by differences in the graphite target depths (since we press our samples from the front). As our ${ }^{14} \mathrm{C}$ data shows, machine-induced isotopic fractionation correction with on-line $\delta^{13} \mathrm{C}$ AMS point by point (e.g. from single sputtering periods) is essential for achieving reliable results.

- Background determinations of the $\mathrm{MC}$ and $\mathrm{DC}$ components by measuring several ${ }^{14} \mathrm{C}$-free (Figure 1a) and modern graphite targets (Figure 1b) spanning a range of sizes, and subjected to the same sample processing as the unknowns: Mass-balance background corrections can then be applied to all samples measured in a given sample wheel (detailed formulas presented in Santos et al. 2007a).

- Recent improvements in the calibration of the dynamic range for our current measurement system allow us to use the same set of 6 regular normalizing standards ( $1 \mathrm{mg} \mathrm{C} \mathrm{OX-I)} \mathrm{during} \mathrm{anal-}$ yses of ultra-small samples $(<0.010 \mathrm{mg} \mathrm{C})$ (Beverly et al. 2010). In this way, no special measurement setup with smaller or matching size normalizing standards is necessary to achieve precisions of $\sim 1 \%$ determined on standards of $\sim 0.010 \mathrm{mg} \mathrm{C}$.

It is necessary to continuously check that these requirements are satisfied by measuring standards in a range of sizes and ${ }^{14} \mathrm{C}$ activities (in a single wheel to eliminate any tuning variability), and when possible, from materials with the same composition as the unknown samples. Figure 3 shows results from some of our secondary standards. The IAEA series help us to evaluate background corrections and measurement performance of samples subjected to combustion and graphitization only, while FIRI-C and FIRI-D are used to assess carbonate hydrolysis and the pretreatment applied to organic samples, respectively. These and other secondary standards are regularly used by our lab to verify all pretreatments, $\mathrm{CO}_{2}$ production, and graphitization procedures. Note that since both the $\mathrm{MC}$ and $\mathrm{DC}$ contamination vary from batch to batch and from wheel to wheel (for a given measuring day), corrections and uncertainties are calculated for each batch that will force the corrected data for all standards measured to lie within $\pm 2 \sigma$ of the consensus value.

Although we can produce and measure samples $\sim 0.001 \mathrm{mg} \mathrm{C}$ (Santos et al. 2010), for conventional ${ }^{14} \mathrm{C}$ analyses we only report results from outside samples $\geq 0.015 \mathrm{mg} \mathrm{C}$. In addition, we always encourage submitters to provide enough material to produce regular-sized samples $(0.7 \mathrm{mg} \mathrm{C})$. Samples that provide low $\mathrm{CO}_{2}$ yields after pretreatment may have been heavily contaminated in situ, and so the source of the small residual amounts of $\mathrm{C}$ is suspect. 

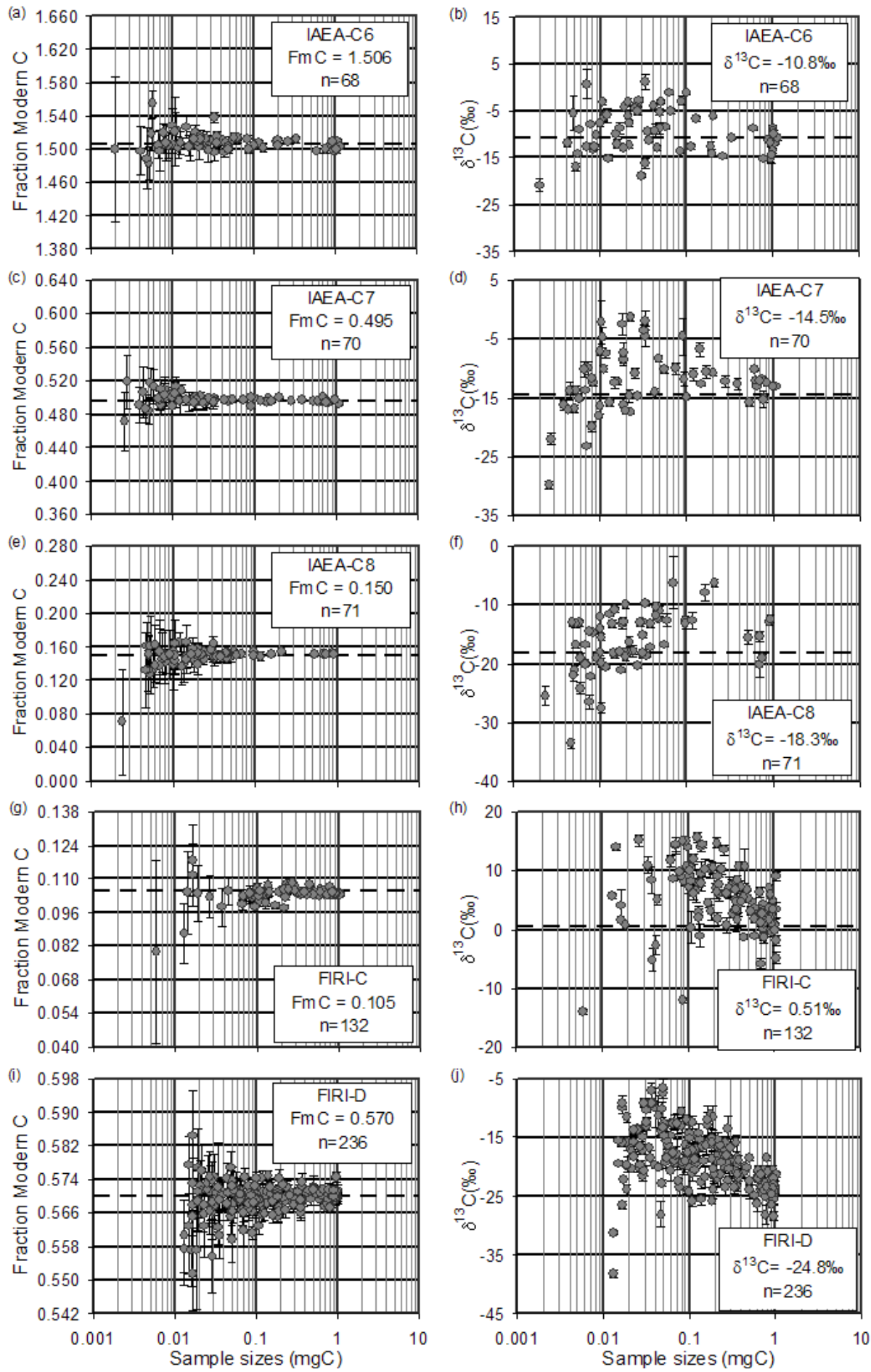

Figure 3 Secondary standards: fraction modern carbon and $\delta^{13} \mathrm{C}$ results for all IAEA standards, FIRI-C, and D samples between $\sim 0.002$ and $\sim 1 \mathrm{mg} \mathrm{C}$ from multiple ${ }^{14} \mathrm{C}$ AMS measurements. All results have been corrected for MC and DC contamination (blank subtraction formulas given in Santos et al. 2007a) as well as for isotopic fractionation with on-line $\delta^{13} \mathrm{C}$ AMS values. 


\section{Chemical Extraction and Separation Blank}

Since the goal of CSRA is to isolate individual biomarkers from larger compound classes (e.g. amino acids, lipids, and carbohydrates), samples are usually in the submilligram range (Ingalls and Pearson 2005). Moreover, many procedural factors can introduce considerable amounts of ${ }^{14} \mathrm{C}$-modern or -dead carbon (MC or DC) contamination that may or may not be detected using traditional analytical tools. For example, chemical extraction, reaction, and purification protocols likely entrain high-molecular-weight residues (stabilizers, plasticizers, char, etc.) from processing containers, equipment, derivatization reagents, and solvents. Subsequent preparative gas or liquid chromatographic (GC or LC) steps may also introduce contamination via column bleed and carryover from previous injections. Such effects are expected to primarily depend on sample volume, injection method, and column parameters (stationary phase composition and thickness, length, service history, and oven temperature). The combined extra C introduced by these steps (the CSRA method) is the $\mathrm{C}_{c}$ fraction for these procedures (Equation 2), and must be quantified. Ideally, CSRA blanks associated with these procedures should be evaluated either directly, in which a "virtual" sample (carrier-only or no-sample) is carried through all of the steps applied to the unknowns, or indirectly, wherein small aliquots of standards whose ${ }^{14} \mathrm{C}$ compositions are known a priori (preferably including both ${ }^{14} \mathrm{C}$-modern and -dead end-members) are treated as unknowns.

Note that this chemistry blank cannot be disregarded even if the conventional combustion and graphitization steps are removed from the AMS sample preparation procedure (e.g. if an elemental analyzer is used to produce $\mathrm{CO}_{2}$ to feed an AMS system ion-source, for example). The removal of the conventional combustion and graphitization steps may reduce a small fraction of the $\mathrm{C}_{h}$ parameter (from Equation 2); however, it will not reduce the $\mathrm{C}_{c}$ fraction from a full CSRA procedure.

\section{CSRA CASE STUDIES}

In order to illustrate how blanks involved from chemical extraction and compound separation can be effectively determined, both direct and indirect assessments undertaken as part of several CSRA studies are described below. Note that for each study, a unique approach to determinate the blanks was attempted, illustrating that no single ideal recipe is available to evaluate the modern and fossil carbon contaminations ( $\mathrm{MC}$ and DC blanks) from these procedures. More detailed project objectives and unknown sample ${ }^{14} \mathrm{C}$ data can be found in the corresponding references.

The CSRA blank results discussed in the following sections do not include any combustion and graphitization carbon contributions, as their contributions from MC and DC contaminations had already been subtracted using information obtained from graphite standards (subjected to combustion and graphitization only) measured on the same wheels as the CSRA unknowns and standards.

\section{Fatty Acids in Marine Sediments}

In order to investigate the temporal dynamics of terrestrial organic matter transport to the oceans, unbound fatty acids were isolated from the sediments of 3 continental margin sites using the methods described in Drenzek et al. (2009). The $n \mathrm{C}_{16}, n \mathrm{C}_{24}, n \mathrm{C}_{26}$, and $n \mathrm{C}_{28}$ homologues, as well as the $n \mathrm{C}_{14+18}$ and $n \mathrm{C}_{30+32}$ homologue combinations, were isolated for CSRA by preparative capillary gas chromatography (PCGC) and combusted to $\mathrm{CO}_{2}$ following the techniques of Eglinton et al. (1996). The chemical extraction described, PCGC separation, and combustion of samples were conducted at the Woods Hole Oceanographic Institute (WHOI). Therefore, in order to assess the blank contributions from the WHOI combustion vacuum line, $12 \mathrm{OX}$-I and 8 neat $n \mathrm{C}_{19}$ alcohol standards (bulk) of

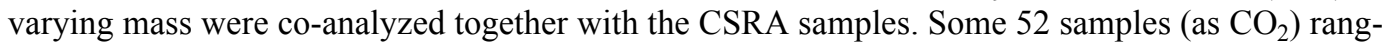


ing in size from 0.005 to $0.063 \mathrm{mg} \mathrm{C}$ were then sent, graphitized, and analyzed at the KCCAMS facility, following the methods of Santos et al. (2004, 2007a).

For indirect $\mathrm{MC}$ and $\mathrm{DC}$ blank assessments associated with the full procedure (i.e. extraction through AMS analysis), a solution of mixed standards whose isotopic compositions encompass the full $\Delta{ }^{14} \mathrm{C}$ scale $\left(n \mathrm{C}_{19}\right.$ alcohol, $\Delta{ }^{14} \mathrm{C}=-999 \% ; n \mathrm{C}_{21}$ fatty acid, $\Delta^{14} \mathrm{C}=-389 \%$; iso- $\mathrm{C}_{21}$ fatty acid, $\Delta^{14} \mathrm{C}=-32.9 \%$ ) was added to separate precombusted aliquots of sea sand in several mass increments over the sample mass range, extracted, isolated into individual compounds, graphitized, and analyzed on the same AMS wheels according to the methods described above. The ${ }^{14} \mathrm{C}$ activity ratios of the $n \mathrm{C}_{19}$ alcohol to OX-I measured for the entire procedure and for the combustion and graphitization steps only are shown in Figure 4a. Appreciable scatter about the isolines suggest that the mass of the MC blank was not constant, especially during the combustion/graphitization stages. Results for the $n$ - and $i s o \mathrm{C}_{21}$ fatty acid standards reflect similar variability, whereas the OX-I standards closely adhere to bulk values above $0.010 \mathrm{mg} \mathrm{C}$ and then systematically trend toward enriched values (after background corrections) at ultra-low masses (Figure $4 \mathrm{~b}$ ). Based on these data, total masses and mass errors of extraneous MC and DC were determined to be $0.8 \pm 0.4 \mu \mathrm{g} \mathrm{C}$ (all derived from combustion/graphitization) and $1.0 \pm 0.5 \mu \mathrm{g} \mathrm{C} \mathrm{(75 \%} \mathrm{derived} \mathrm{from} \mathrm{the} \mathrm{sample} \mathrm{preparation} \mathrm{steps}$ preceding combustion), respectively. Note that to have all ${ }^{14} \mathrm{C}$ results from small standards fall within $\pm 2 \sigma$ of the true value, an error of $50 \%$ of the $\mathrm{MC}$ and $\mathrm{DC}$ calculated values was then imposed into their background subtractions.

\section{Phospholipid Fatty Acids (PLFAs) in ${ }^{14} \mathrm{C}$-Elevated Soils}

The following studies were carried out exclusively at UCI using our PCGC system (Hewlett Packard 6890 outfitted with a Gerstel cooled injection system and a flame ionization detector [FID]). In an effort to quantify the contribution of leaf litter carbon to microbial biomarker inventories, surface soil samples $(0-10 \mathrm{~cm})$ from a plot that had experienced elevated- ${ }^{14} \mathrm{C}$ input were compared with a plot with natural- ${ }^{14} \mathrm{C}$ litter additions. Field-moist soil samples $(200-500 \mathrm{~g}$; physically cleaned of roots and plant material) were extracted with chloroform, methanol, and acetone to separate the phospholipid fraction. Phospholipids were derivatized by mild alkaline methanolysis using a methanolic potassium hydroxide solution of known carbon isotopic composition to obtain fatty acid methyl esters (FAMEs), which were further apportioned into saturated, monounsaturated, and polyunsaturated fractions using aminopropyl- and silver nitrate $\left(\mathrm{AgNO}_{3}\right)$-impregnated solid phase extraction (SPE) columns (Zelles 1999). Individual compounds from each of these fractions were subsequently isolated by PCGC. Sequential injections were performed to isolate $0.010-0.050 \mathrm{mg} \mathrm{C}$ per homologue. Purified FAMEs were eluted into storage vials using dichloromethane and, at a later date, transferred to precleaned quartz combustion tubes, then dried down the solvent with $\mathrm{N}_{2}$ before combustion graphitization for AMS sample preparation. A detailed description of procedures and PCGC settings is presented in Kramer et al. (2010).

The PCGC blank was assessed by isolating ${ }^{14} \mathrm{C}$-modern FAME standards $\left(n \mathrm{C}_{16}\right.$ and $\left.n \mathrm{C}_{18}\right)$ into a metal alloy GC column (CP-Sil 8 CB UltiMetal column; $50 \mathrm{~m} \times 0.53 \mathrm{~mm}$ ID, $0.5-\mu \mathrm{m}$ film thickness), which was also shared for a short period of time with another user who was isolating a different set of compounds. Each wheel or batch of unknowns measured had at least 4 and up to 6 samples of those FAME standards $\left(n \mathrm{C}_{16}\right.$ and $\left.n \mathrm{C}_{18}\right)$ that were isolated in different amounts spanning the range of our samples (e.g. from 0.01 to $1 \mathrm{mg} \mathrm{C}$ ). After ${ }^{14} \mathrm{C}$ AMS measurements, significant depletion in ${ }^{14} \mathrm{C}$ (due to fossil carbon input) of the modern FAME standards was observed, in which the GC blank DC component seemed to vary from 0 to $0.002 \mathrm{mg} \mathrm{C}$ (once the size-dependent corrections for graphitization and combustion had already been made). After systematic investigations carried between 2006 to 2009 (a total of 15 wheels carrying 2-11 PCGC processed standards, ranging from 

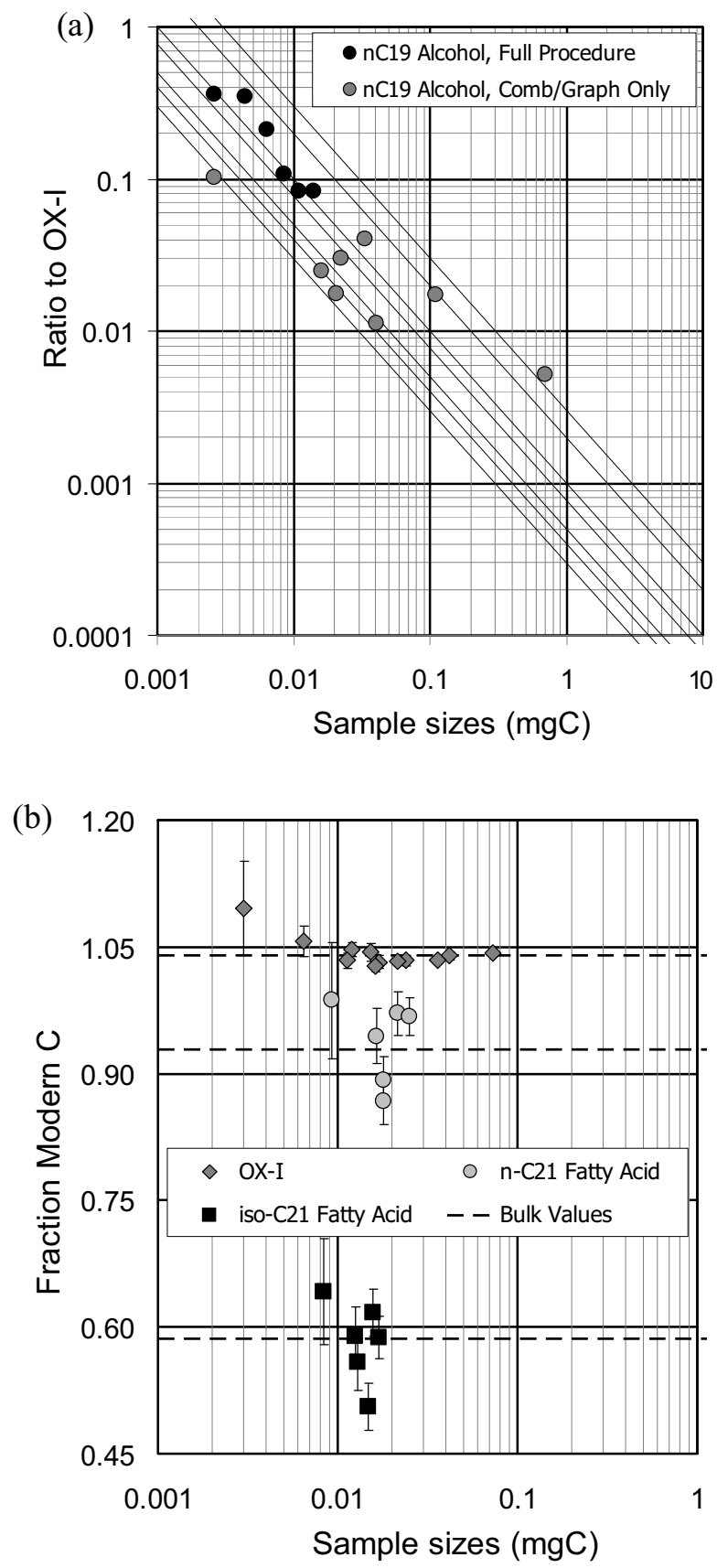

Figure 4 (a) Indirect MC contamination assessment for the full CSRA procedure (black symbols) and combustion + graphitization steps only (gray symbols) using $n \mathrm{C}_{19}$ alcohol standard $\left(\Delta{ }^{14} \mathrm{C}=-999 \%\right.$ ). Diagonal lines represent fixed amounts of MC contamination from 0.2 to $3 \mu \mathrm{g} \mathrm{C}$ (left to right); (b) Indirect DC contamination assessment for the full CSRA procedure $\left(n \mathrm{C}_{21}\right.$ fatty acids, light gray circles) and combustion + graphitization steps only (OX-I, dark gray diamonds). Measured values for a standard of intermediate radiocarbon composition (iso $\mathrm{C}_{21}$ fatty acids, black squares) are also shown. Horizontal dashed lines denote the corresponding consensus values based on bulk-level measurements. All data were corrected for machine-induced isotopic fractionation. 
0.006- $0.120 \mathrm{mg} \mathrm{C}$ ), we concluded that the occasional large amount of DC observed was associated with the combination of memory and column bleeding (from the PCGC column alone) and dichloromethane solvent residue (that also contributed to sample yield discrepancies). Given this large and variable blank, CSRA results from unknown FAME samples produced during this phase with $<0.010 \mathrm{mg} \mathrm{C}$ were disregarded. Due to $\mathrm{DC}$ high variability, the remaining ${ }^{14} \mathrm{C}$ results were then background-corrected by an average DC blank of $0.51 \mu \mathrm{g} \mathrm{C}(n=73)$ with an imposed error bar greater than $50 \%$ (to force all PCGC-processed FAME standards to fall within $\pm 2 \sigma$ of the consensus value). FAME ${ }^{14} \mathrm{C}$ data were also corrected for the addition of $1{ }^{14} \mathrm{C}$-free methyl $\mathrm{C}$, which was added during derivatization with methanol/KOH solution, to calculate the original ${ }^{14} \mathrm{C}$ signature of the PLFA. For this project, MC contamination was not evaluated because a dead-FAME standard was not available. Since samples of interest were in the modern or near-modern ${ }^{14} \mathrm{C}$ range with values closer to the DC FAME standards measured, we assumed that the MC correction should be small or negligible. More recently, the MC PCGC FAME contamination was estimated, by measuring a ${ }^{14} \mathrm{C}-$ free $n \mathrm{C}_{22}$ alkane standard, to be $0.090 \mu \mathrm{g} \mathrm{C}$. As expected, this correction is too small to affect the conclusions already obtained for the PLFAs in ${ }^{14} \mathrm{C}$-elevated soils (Kramer et al. 2010).

Reproducibility of the ${ }^{14} \mathrm{C}$ results was also evaluated. First, we repeatedly measured a particular compound with different batches of samples. Second, we also performed duplicate extraction and separation procedures on a single sample and compared the ${ }^{14} \mathrm{C}$ signatures of several PLFA compounds. The final results, after proper background subtractions as described above, showed that our replicate and duplicate samples with $>0.010 \mathrm{mg} \mathrm{C}$ are in good agreement (Kramer et al. 2010).

\section{Phospholipid Fatty Acids (PLFAs) and Alkanes in Ocean Sediments}

The goal of the study of CSRA on surface sediments was to detect bacterial degradation products of marine organic matter (PLFAs) and non-marine sources of organic matter (alkanes) to the coastal region of southern California (Druffel et al. 2010). To obtain single compounds from each of these matrices for CSRA, extraction is required using a variety of techniques. The same extraction scheme used for PLFAs in terrestrial soils described above was used for ocean sediments (Zelles 1999). Alkanes were extracted from the neutral lipid fraction using urea adduction, dissolution in water, acid-cleaning, and extraction through $\mathrm{AgNO}_{3}$-impregnated silica gel (Pearson and Eglinton 2000). Note that for this work, dedicated capillary columns were used in the GC for each compound class isolated and collected to avoid the possibility of cross-contamination. For the PLFAs and alkanes, the GC column was heated from $60-320^{\circ} \mathrm{C}$. Compounds were collected in the multicollector in quartz traps at $-10{ }^{\circ} \mathrm{C}$, then combusted to $\mathrm{CO}_{2}$ and reduced to graphite for AMS analysis (Santos et al. 2007a).

Blank assessment for PLFAs and alkanes was conducted in the same manner as that described above. The metal GC column (CP-Sil 8 CB UltiMetal column; $50 \mathrm{~m} \times 0.53 \mathrm{~mm}$ ID, $0.5-\mu \mathrm{m}$ film thickness; phase: $5 \%$ phenyl $95 \%$ dimethylpolysiloxane) was replaced with DB-XLB capillary column $(30 \mathrm{~m} \times 0.53 \mathrm{~mm}$ ID, $1.5-\mathrm{mm}$ film thickness). Recent evaluations of the direct DC contributions coming from this new GC column gave a lower average background of $0.25 \mu \mathrm{g} \mathrm{C} / \mathrm{min} / 50$ injections $(n=5)$ than that using the previous GC column. Additionally, a remarkably low DC value of $0.093 \mu \mathrm{g} \mathrm{C} / \mathrm{min} / 50$ injections $(n=1)$ was obtained by transferring the multicollector traps themselves to the combustion tubes (to eliminate solvent-associated blank previously added during the transfer of sample). An evaluation of the MC contribution was performed using a dead $n \mathrm{C}_{22}$ alkane and yielded a $0.09 \mu \mathrm{g} \mathrm{C} / \mathrm{min} / 50$ injections collection time. The blank $\mathrm{C}$ from the combined chemical extraction and PCGC (assessed recently) yielded a total blank mass ranged from 0.09 to $0.17 \mu \mathrm{g} \mathrm{C} /$ $\mathrm{min} / 50$ injections, with a combined ${ }^{14} \mathrm{C}$ value of $-635 \pm 21 \%$. 
Table 1 Summary of direct and indirect blank assessment of the BPCA method against the GC column.

\begin{tabular}{|c|c|c|c|c|c|c|c|}
\hline Approach & Sample material & $\begin{array}{l}\text { BPCA } \\
\text { formation }\end{array}$ & $\mathrm{CH}_{2} \mathrm{Cl}_{2}$ & PCGC & $\begin{array}{l}\text { Av. graphite } \\
\text { size }(\mu g \mathrm{C})\end{array}$ & $\begin{array}{l}\Delta^{14} \mathrm{C} \pm \mathrm{Er} . \\
(\%)\end{array}$ & $\begin{array}{l}\text { Total blank } \pm \text { Er. }{ }^{\mathrm{a}} \\
(\mu \mathrm{g} \mathrm{C} / \mathrm{min} / 50 \text { inj) }\end{array}$ \\
\hline \multirow[t]{3}{*}{$\begin{array}{l}\text { Direct } \\
\text { blank }\end{array}$} & $\begin{array}{l}\text { Dry injections } \\
\text { (GC only; } 400 \text { inj) }\end{array}$ & no & no & yes & $7.6(n=1$ & $-875 \pm 34$ & 0.1 \\
\hline & $\begin{array}{l}\text { Total blank w/o } \\
\text { sample ( } 50 \text { inj) }\end{array}$ & yes & yes & yes & $\begin{array}{l}7.6 \pm 1.6 \\
(n=7)\end{array}$ & $-800 \pm 54$ & $1.1 \pm 0.2$ \\
\hline & $\begin{array}{l}\text { Total blank w/o } \\
\text { sample }(50 \text { inj })^{b}\end{array}$ & yes & yes & yes & $\begin{array}{l}4.1 \\
(n=1)\end{array}$ & $-940 \pm 40$ & 0.08 \\
\hline \multirow[t]{4}{*}{$\begin{array}{l}\text { Indirect } \\
\text { blank }\end{array}$} & $\begin{array}{l}\text { Synthetic vanillin } \\
\left({ }^{14} \mathrm{C} \text { free; } 50 \mathrm{inj}\right)\end{array}$ & no & yes & yes & $\begin{array}{l}2 \text { to } 65 \\
(n=5)\end{array}$ & enriched $^{c}$ & $0.5 \pm 0.3^{\mathrm{d}}$ \\
\hline & $\begin{array}{l}\text { Natural Vanillin } \\
\text { (modern; } 50 \text { inj) }\end{array}$ & no & yes & yes & $\begin{array}{l}8 \text { to } 71 \\
(n=5)\end{array}$ & depleted $^{\mathrm{e}}$ & \\
\hline & $\begin{array}{l}\text { Hexane soot } \\
\left({ }^{14} \mathrm{C} \text { free; } 50 \text { inj }\right)\end{array}$ & yes & yes & yes & $\begin{array}{l}2 \text { to } 9 \\
(n=6)\end{array}$ & enriched $^{c}$ & $1.1 \pm 0.7^{\mathrm{d}}$ \\
\hline & $\begin{array}{l}\text { Grass char } \\
\text { (modern; } 50 \text { inj) }\end{array}$ & yes & yes & yes & $\begin{array}{l}2 \text { to } 16 \\
(n=7)\end{array}$ & depleted $^{\mathrm{e}}$ & \\
\hline
\end{tabular}

${ }^{a}$ The error (Er.) of the total blank was determined by the range in the blank data.

${ }^{b}$ Later test of total blank, using a different batch of reagents, collected 4 months later.

${ }^{\mathrm{c}}{ }^{14} \mathrm{C}$ results appeared enriched before mass-balance blank correction.

${ }^{\mathrm{d}}$ Final results from indirect blank assessment correspond to the sum of the 2 end-member components MC and DC.

${ }^{\text {e }}{ }^{14} \mathrm{C}$ results appeared depleted before mass-balance blank correction.

\section{Black Carbon in Marine DOC Using the Benzene Polycarboxylic Acid (BPCA) Method}

The goal of the study of CSRA on black carbon (BC) from dissolved organic carbon (DOC) was to estimate the residence time of combusted organic matter in ocean water. Black carbon was oxidized in nitric acid at $180{ }^{\circ} \mathrm{C}$ for $8 \mathrm{hr}$, and the resultant benzene polycarboxylic acids were filtered and derivatized with diazomethane. For the BPCAs, the GC column was heated from $100-280{ }^{\circ} \mathrm{C}$; an injection volume of $1 \mu \mathrm{L}$ was used exclusively.

For the BPCAs, the CSRA blank was assumed to originate from 2 sources: (a) the chemical extraction of BC and (b) the PCGC during sample isolation and concentration. Using both direct and indirect blank assessment, we evaluated the CSRA blank from these 2 sources. Between samples, the injection temperature ramp, oven temperature, number of injections, and PFC collection temperature were maintained; only the volume of sample or solvent injected or collection window varied.

The extraneous $\mathrm{C}$ added during PCGC isolation was directly assessed by performing 400 dry injections (no solvent injected) and collecting a 7-min retention time window. The collection window duration was selected to reflect the range of times over which BPCAs elute from the GC column and to produce a sample large enough for ${ }^{14} \mathrm{C}$ analysis. The indirect assessment of the CSRA blank originating from the PCGC only was performed using modern and dead vanillin collected for 0.6-1.8 min over 50 injections. To relate the direct and indirect assessment of the CSRA blank, we elected to express the amount of blank added in $\mu \mathrm{g} \mathrm{C}$ per minute of collection per 50 injections. When evaluated directly, the blank added during PCGC processing was $0.1 \mu \mathrm{g} \mathrm{C} / \mathrm{min} / 50$ injection with $\Delta^{14} \mathrm{C}=$ $-875 \pm 34 \%$. Using $\mathrm{MC}$ and $\mathrm{DC}$ components of this blank, the indirect analysis of the total carbon added during PCGC processing was $0.5 \pm 0.3 \mu \mathrm{g} \mathrm{C} / \mathrm{min} / 50$ injections with $\Delta{ }^{14} \mathrm{C}=-800 \pm 100 \%$.

Next, we evaluated the extraneous $\mathrm{C}$ added during the chemical extraction and PCGC processing combined (full chemical/separation processing blank). When evaluated directly, this blank was $1.1 \pm 0.2 \mu \mathrm{g} \mathrm{C} / \mathrm{min} / 50$ injections with $\Delta^{14} \mathrm{C}=-800 \pm 54 \%$. The indirect assessment of this blank was performed by using BC-rich standard reference materials, hexane soot (dead) and grass char 
(modern), collected for between 0.7 and 3.7 min over 50 injections. When the MC and DC components of the indirect blank analysis were summed, the total blank from chemical extraction and PCGC separation (full CSRA blank) was $1.0 \pm 0.5 \mu \mathrm{g} \mathrm{C} / \mathrm{min} / 50$ injections with $\Delta^{14} \mathrm{C}=-850 \pm 50 \%$.

Direct and indirect analyses of the BPCA blank agree, that is, the full BPCA method adds twice as much carbon as that added from the GC column bleed alone. The blank assessments presented above were conducted over a 3-month period. Later tests, using different batches of solvents, reveal that the carbon added during the chemical extraction and PCGC processing of samples can vary significantly in magnitude and ${ }^{14} \mathrm{C}$ (Table 1). Detailed blank assessment can be found in Ziolkowski and Druffel (2009).

\section{CONCLUSIONS}

In principle, the KCCAMS facility can routinely produce and measure samples $\cong 0.001 \mathrm{mg} \mathrm{C}$. However, for conventional submissions from external clients, we only report results from graphite samples $\geq 0.015 \mathrm{mg} \mathrm{C}$ with $\sim 1 \%$ precision on standards as small as $\sim 0.010 \mathrm{mg}$ C. Although AMS technology allows extremely small amounts of material to be analyzed, the main analytical challenge confronting ultra-small CSRA measurements remains the entrainment of extraneous $\mathrm{C}$ contaminants during the purification process. In some cases, the magnitude of the blanks may be so high that results are meaningless if low processing yields result in very small samples. Since the quality of the CSRA scientific information depends fundamentally on the quality of the underlying measurement process, frequent evaluation of the background signal is necessary in order to fully capture the variability arising from assorted laboratory techniques, different equipment, and intrinsic sample heterogeneity.

\section{REFERENCES}

Beaupré SR, Druffel ERM, Griffin S. 2007. A lowblank photochemical extraction system for concentration and isotopic analyses of marine dissolved organic carbon. Limnology and Oceanography 5:174 84.

Beverly RK, Beaumont W, Tauz D, Patel S, Ormsby KM, von Reden K, Santos GM, Southon JR. 2010. The Keck Carbon Cycle AMS Laboratory, University of California, Irvine: status report. Radiocarbon 52(23):301-9.

Brown TA, Southon JR. 1997. Corrections for contamination background in AMS ${ }^{14} \mathrm{C}$ measurements. $\mathrm{Nu}$ clear Instruments and Methods in Physics Research $B$ 123(1-4):208-13.

Drenzek NJ, Hughen KA, Montluçon DB, Southon JR, dos Santos GM, Druffel ERM, Giosan L, Eglinton TI. 2009. A new look at old carbon in active margin sediments. Geology 37(3):239-42.

Druffel ERM, Zhang D, Xiaomei Xu X, Ziolkowski LA, Southon JR, Santos GM, Trumbore SE. 2010. Compound-specific radiocarbon analyses of phospholipid fatty acids and $n$-alkanes in ocean sediments. Radiocarbon 52(2-3):1215-23.

Eglinton TI, Aluwihare LI, Bauer JE, Druffel ERM, McNichol AP. 1996. Gas chromatographic isolation of individual compounds from complex matrices for radiocarbon dating. Analytical Chemistry 68(5):904-12.

Hwang J, Druffel E, Komada T. 2005. Transport of organic carbon from the California coast to the slope re- gion: a study of $\Delta^{14} \mathrm{C}$ and $\Delta^{13} \mathrm{C}$ signatures of organic compound classes. Global Biogeochemical Cycles 19: GB2018, doi:10.1029/2004GB002422.

Ingalls AE, Pearson A. 2005. Ten years of compound specific radiocarbon analysis. Oceanography 18(3): 18-31.

Ingalls AE, Shah SR, Hansman RL, Aluwihare LI, Santos GM, Druffel ERM, Pearson A. 2006. Quantifying archaeal community autotrophy in the mesopelagic ocean using natural radiocarbon. Proceedings of the National Academy of Sciences of the USA 103(17: 6442-7.

Kirner DL, Taylor RE, Southon JR. 1995. Reduction in backgrounds of microsamples for AMS ${ }^{14} \mathrm{C}$ dating. Radiocarbon 37(2):697-704.

Kramer C, Trumbore S, Fröberg M, Cisneros Dozal LM, Zhang D, Xu X, Santos GM, Hanson PJ. 2010. Recent ( $<4$ year old) leaf litter is not a major source of microbial carbon in a temperate forest mineral soil. Soil Biology and Biochemistry Journal 42(7):1028-37.

Middleton R, Juenemann D, Klein J. 1994. Isotopic fractionation of negative ions produced by Cs sputtering in a high-intensity source. Nuclear Instruments and Methods in Physics Research B 93(1):39-51.

Muller RA. 1977. Radioisotope dating with a cyclotron. Science 196(4289):489-94.

Nelson DE, Korteling RG, Stott WR. 1977. Carbon-14: direct detection at natural concentrations. Science 198(4316):507-8. 
Olsson IU. 2009. Radiocarbon dating history: early days, questions, and problems met. Radiocarbon 51(1):143.

Pearson A, Eglinton T. 2000. The origin of $n$-alkanes in Santa Monica Basin surface sediment: a model based on compound-specific $\Delta^{14} \mathrm{C}$ and $\delta^{13} \mathrm{C}$ data. Organic Geochemistry 31(11):1103-16.

Pearson A, Ingalls AE, Shah SR, Hansman RL, Aluwihare LI, Santos GM, Griffin S, Druffel ERM. 2005. Exploring the minimum sample size limit for CSRA: lessons from the water column [abstract]. 10th International Conference on Accelerator Mass Spectrometry, Berkeley, California, USA, 5-10 September 2005.

Quarta G, D'Elia M, Calcagnile L. 2004. The influence of injection parameters on mass fractionation phenomena in radiocarbon analysis. Nuclear Instruments and Methods in Physics Research B 217(4):644-8.

Santos GM, Southon JR, Druffel-Rodriguez K, Griffin S, Mazon M. 2004. Magnesium perchlorate as an alternative water trap in AMS graphite sample preparation: a report on sample preparation at the KCCAMS Facility at the University of California, Irvine. Radiocarbon 46(1):165-73.

Santos GM, Southon JR, Griffin S, Beaupre SR, Druffel ERM. 2007a. Ultra small-mass AMS ${ }^{14} \mathrm{C}$ sample preparation and analyses at KCCAMS/UCI Facility. $\mathrm{Nu}$ clear Instruments and Methods in Physics Research B (259):293-302.

Santos GM, Mazon M, Southon JR, Rifai S, Moore R. 2007b. Evaluation of iron and cobalt powder brands for suitable catalyst for ${ }^{14} \mathrm{C}$-AMS target preparation. Nuclear Instruments and Methods in Physics Research B 259(1):308-15.
Santos GM, Moore RB, Southon JR, Griffin S, Hinger E, Zhang D. $2007 \mathrm{c}$. AMS ${ }^{14} \mathrm{C}$ sample preparation at the KCCAMS/UCI Facility: status report and performance of small samples. Radiocarbon 49(2):255-69.

Santos GM, Alexandre A, Coe HHG, Reyerson PE, Southon JR, De Carvalho CN. 2010. The phytolith ${ }^{14} \mathrm{C}$ puzzle: a tale of background determinations and accuracy tests. Radiocarbon 52(1):113-28.

Shah SR, Pearson A. 2007. Ultra-microscale (5-25 $\mu \mathrm{g} \mathrm{C}$ ) analysis of individual lipids by ${ }^{14} \mathrm{C}$ AMS: assessment and correction for sample processing blank. Radiocarbon 49(1):69-82.

Southon J, Santos GM. 2007. Life with MC-SNICS. Part II: recent ion source development at the Keck Carbon Cycle AMS Facility. Nuclear Instruments and Methods in Physics Research B 259(1):88-93.

Vogel JS, Nelson DE, Southon JR. 1987. ${ }^{14} \mathrm{C}$ background levels in an accelerator mass spectrometry system. $R a$ diocarbon 29(3):323-33.

Zelles L. 1999. Fatty acid patterns of phospholipids and lipopolysaccharides in the characterisation of microbial communities in soil: a review. Biology and Fertility of Soils 29(2):111-29.

Zencak Z, Reddy CM, Teuten EL, Xu L, McNichol AP, Gustafsson Ö. 2007. Evaluation of gas chromatographic isotope fractionation and process contamination by carbon in compound-specific radiocarbon analysis. Analytical Chemistry 79(5):2042-9

Ziolkowski LA, Druffel ERM. 2009. Quantification of extraneous carbon during compound specific radiocarbon analysis of black carbon. Analytical Chemistry 81(24):10,156-61. 